1 Universidade Federal do Paraná (UFPR) - Curitiba (PR), Brasil.

deivianna@gmail.com

2 Universidade Estadual de Campinas (Unicamp) Campinas (SP), Brasil

\section{A Gestão Autônoma da Medicação em Centros de Atenção Psicossocial de Curitiba (PR)}

\author{
Autonomous Medication Management in Psychosocial Care Centers \\ of Curitiba (PR)
}

Deivisson Vianna Dantas dos Santos ${ }^{\mathbf{1}}$, Chayanne Federhen ${ }^{\mathbf{1}}$, Thiago Augusto da Silva ${ }^{\mathbf{1}}$, Isabella Renata dos Santos', Caroline de Azevedo Levino', Rosana Teresa Onocko-Campos², Sabrina Stefanello ${ }^{1}$

DOI: $10.1590 / 0103-11042020 E 315$

RESUMO No contexto do 'recovery' surgiu, em 1993, a Gestão Autônoma da Medicação, uma estratégia que visa garantir, aos usuários de psicotrópicos, participação nas decisões relativas aos seus tratamentos, via diálogo e troca de informações entre os envolvidos nos tratamentos em saúde mental com trabalhos nacionais, que demonstram esses efeitos. O objetivo do presente estudo foi fomentar e avaliar qualitativamente a realização da estratégia Gestão Autônoma da Medicação nos Centros de Atenção Psicossocial de Curitiba (PR). Foi feita uma pesquisa qualitativa, com implantação de grupos Gestão Autônoma da Medicação e de entrevistas semiestruturadas. Participaram usuários, trabalhadores dos Centros de Atenção Psicossocial e estudantes de medicina, totalizando 18 entrevistados. O material foi transcrito integralmente e as percepções dos participantes foram avaliadas baseando-se na hermenêutica gadameriana, extraindo-se, assim, núcleos argumentais, os quais foram agrupados em categorias e analisados posteriormente. Demonstrou-se que o grupo Gestão Autônoma da Medicação auxiliou os usuários no processo de conhecimento e tomada de decisão sobre seus tratamentos, bem como no conhecimento dos seus direitos. A intervenção também se mostrou relevante para os profissionais e estudantes, reforçando conceitos como a importância de valorizar a fala, as experiências e a autonomia do usuário.

PALAVRAS-CHAVE Saúde mental. Reabilitação psiquiátrica. Medicalização. Empoderamento para a saúde. 


\section{Introdução}

O sofrimento mental é um fenômeno universal. Todo ser humano, em determinado momento da sua trajetória, poderá vivenciá-lo. Por outro lado, a vivência deste sofrimento é uma experiência única, individual e intransferível, ainda que este processo seja influenciado pelo contexto sociocultural, pelo momento histórico, pelas crenças e pelo ambiente no qual a pessoa habite.

Até a década de 1980, o modelo de tratamento em saúde mental vigente no Brasil era essencialmente hospitalocêntrico e considerava pouco a dimensão da experiência no seguimento do indivíduo. A internação não se relacionava com uma demanda clínica da pessoa, mas sim, com uma demanda da sociedade, institucionalizando o sujeito dentro de uma política que se mostrou segregacionista e punitiva. Esse modelo manicomial produzia diversos efeitos nocivos às pessoas, tais como: perda das habilidades para atividades da vida diária e progressiva desconexão com seus laços sociofamiliares e comunitários ${ }^{\mathbf{1}}$.

A partir da Reforma Psiquiátrica Brasileira, uma nova política de saúde mental foi instituída no país e teve como um dos seus principais recursos os Centros de Atenção Psicossocial (Caps), locais onde o tratamento se desenvolveria de forma comunitária e compartilhada. Apesar das mudanças instituídas, muitos foram e são os desafios na execução deste modelo. Há, ainda, uma primazia do tratamento medicamentoso, sendo que, muitas vezes, este se reduz ao uso de psicotrópicos. O modelo médico-centrado ainda prevalece, especialmente quando se trata da assistência ao usuário de saúde-mental, sendo a sua participação, muitas vezes, restringida ao mero relato dos sintomas ${ }^{2}$. Ademais, o redirecionamento recente da política de saúde mental brasileira, na qual o financiamento dos equipamentos territoriais é diminuído em prol do aumento do investimento em hospitais psiquiátricos, comunidades terapêuticas e outros equipamentos de grande porte, tende a reduzir ainda mais a participação dos usuários nos rumos dos seus tratamentos ${ }^{3}$.

Na década de 1990, nasce a Gestão Autônoma da Medicação (GAM), uma proposta que surgiu no Canadá, a partir dos questionamentos feitos à gestão da prescrição de psicotrópicos aos pacientes de saúde mental4. A GAM surge no contexto do movimento de recovery (processo de reestabelecimento) em saúde mental, que foi um movimento iniciado na década de 1970, em países anglo-saxões, mobilizado por pessoas com diagnóstico de esquizofrenia, em defesa da compreensão de que os indivíduos não poderiam ser reduzidos aos diagnósticos de transtornos mentais 4 . O movimento recovery compreende que a doença é apenas uma das esferas da vida humana e abre espaço para a recuperação/reestabelecimento capaz de conviver com a condição de adoecimento, sem necessariamente a total remissão dos sintomas. O recovery é um processo dinâmico, não linear, e tem, como possíveis espaços para seu desenvolvimento, grupos de mútua ajuda, movimentos pelos direitos civis e de valorização dos usuários ${ }^{\mathbf{5}}$.

Nesse sentido, a GAM indaga sobre a falta de informações relacionadas aos remédios prescritos; os efeitos indesejáveis decorrentes do uso destes medicamentos; a persistência do sofrimento, mesmo com o tratamento medicamentoso; a dificuldade de retornar ao mercado de trabalho; o desejo dos usuários, de viverem sem os remédios; e, por fim, a autonomia dos usuários diante das escolhas terapêuticas. Na GAM, a autonomia é compreendida como gestão compartilhada ou cogestão, assim sendo construída na relação com o outro. Aqui se compreende autonomia como a capacidade de conhecer e cuidar de si mesmo, atrelada à constante relação, ao conhecimento e ao cuidado com o outro ${ }^{6}$.

A estratégia GAM visa à criação de espaços e grupos nos quais se possa conversar e refletir sobre os medicamentos e seus efeitos na vida 
de cada um. Questionam-se as relações de poder no tratamento em saúde mental, a fim de garantir aos usuários efetiva participação nas decisões relativas aos seus tratamentos, pressupondo que, para isto, são fundamentais o diálogo e a troca entre os atores envolvidos no processo decisório. Na estratégia GAM, os usuários são instigados a dialogar sobre o significado que a medicação e outras práticas ocupam em suas vidas 4 . Assim, a estratégia se pauta no poder de fala e decisão sobre suas próprias vidas e seus próprios tratamentos, compreendendo que, a partir de um processo de crescimento e fortalecimento pessoal (empowerment ou empoderamento), em conjunto com os demais sujeitos de seu contexto sociocultural, poderiam estar mais seguros e fortalecidos nessas decisões ${ }^{5,6}$.

Há cada vez mais estudos ${ }^{7-9}$ demonstrando que a estratégia GAM possibilita a inserção da pluralidade de experiências e significações acerca do uso de psicofármacos em um espaço de cuidado compartilhado. Além disto, ela inclui ferramentas que oportunizam a auto-observação e a identificação de redes de apoio, o que contribui para que o usuário se aproprie do poder decisório em seu tratamento. Seus efeitos também podem ser vistos em relação aos trabalhadores de saúde, que, ao participarem do grupo GAM, indicaram a ampliação do vínculo entre profissionais e usuários. O contato com a experiência propiciou aos trabalhadores maior crítica em relação à dificuldade de confiar na decisão do usuário sobre o que fazer com o seu tratamento, levando-os a se perceberem com posturas menos tutelares.

Com a difusão da estratégia GAM como uma prática de empoderamento dos usuários no campo da saúde mental no Brasil, faz-se necessário estudar e avaliar as suas consequências em outras regiões e locais. Sendo assim, o objetivo deste estudo é analisar os efeitos e as consequências da implantação da estratégia GAM em Caps do município de Curitiba (PR), seja nos usuários, profissionais da saúde ou estudantes de medicina.

\section{Metodologia}

O presente estudo utilizou-se da metodologia qualitativa do tipo pesquisa-ação, através da implementação de grupos GAM e, posteriormente, de entrevistas semiestruturadas com os participantes do grupo. A pesquisa-ação para este estudo se justifica, uma vez que ela tem por finalidade unir a pesquisa à prática. Com este tipo de pesquisa, é possível intervir na prática de modo inovador já no transcurso do estudo e não apenas ao final do trabalho ${ }^{10}$.

A pesquisa-ação se propõe a intervir em problemas da realidade, visando uma transformação no espaço em que atua, buscando uma relevância prática em seus resultados. Como intervém sobre a realidade, em alguma medida, há a superação entre sujeito de pesquisa e objeto de pesquisa; o trabalho se dá em conjunto, entre pesquisador e local de ação-pesquisa, orientando-se de modo coletivo e participativo ${ }^{10,11}$. Além disto, também pretende avaliar a si mesma, tanto durante o processo como em seus resultados finais. Desta forma, a pesquisa-ação ultrapassa os limites do tradicional estudo de caso ao adicionar o elemento avaliativo à descrição da intervenção.

A fim de apresentar a estratégia aos profissionais que trabalham com saúde mental em Curitiba (PR), sensibilizá-los e ensiná-los sobre o desenvolvimento da GAM, foi oferecido um curso pelo projeto de extensão 'A Gestão Autônoma da Medicação na Rede de Atenção Psicossocial do Município de Curitiba-PR', do Núcleo de Estudos em Saúde Coletiva da Universidade Federal do Paraná (UFPR). O curso ocorreu em agosto de 2017 e contou com sete encontros, cada um com duas horas de duração. Ao término do curso, os profissionais da rede de atenção psicossocial que demonstraram interesse iniciaram grupos GAM nos seus respectivos serviços, contando com a colaboração dos alunos da graduação de medicina, vinculados ao projeto de extensão. Ao todo, foram criados três grupos, que aconteceram em Caps diferentes, no município de Curitiba (PR), sendo um deles voltado para 
pessoas com problemas relacionados ao uso de álcool e outras drogas (Caps AD). Além dos usuários, participaram dos grupos estudantes integrantes do projeto de extensão anteriormente citado e trabalhadores dos serviços, os quais realizavam a mediação dos encontros. A diferença desse trabalho para outros já desenvolvidos, envolvendo a estratégia GAM, foi a inclusão de estudantes como participantes dos grupos, que inclusive acabaram servindo como estratégia de formação, já que estavam ligados a um projeto de extensão.

Cada um dos grupos se desenvolveu nos espaços de seus referidos Caps e as equipes desses serviços foram as responsáveis por convidar os usuários a participarem dos grupos GAM.

Os critérios de inclusão dos usuários para participação na pesquisa foram: participação no grupo; uso de psicofármacos há, pelo menos, um ano; quadro clínico estável; e capacidade de interação dialógica e consentimento (assinatura do Termo de Consentimento Livre e Esclarecido). Exceto pelo consentimento, a observação dos critérios de inclusão foi realizada pelos próprios trabalhadores do Caps, tanto na indicação como no convite de usuários para participação no grupo. O critério de inclusão para estudantes e profissionais foi a participação no grupo GAM, fosse moderando o grupo ou como observador externo (quadro 1).

Quadro 1. Características dos participantes, número, duração dos encontros e entrevistados de cada grupo

\begin{tabular}{|c|c|c|c|c|c|}
\hline Locais & Participantes & $\begin{array}{l}\text { Número de } \\
\text { encontros }\end{array}$ & $\begin{array}{l}\text { Duração de cada } \\
\text { encontro (horas) }\end{array}$ & Duração do grupo & Entrevistados \\
\hline Caps A & $\begin{array}{l}5 \text { usuários } \\
1 \text { profissional } \\
1 \text { estudante }\end{array}$ & 15 & 1 & $\begin{array}{l}\text { Set/2017 a } \\
\text { Jul/2018 }\end{array}$ & $\begin{array}{l}3 \text { usuários } \\
1 \text { trabalhador } \\
1 \text { estudante }\end{array}$ \\
\hline Caps B & $\begin{array}{l}4 \text { usuários } \\
2 \text { profissionais } \\
1 \text { estudante }\end{array}$ & 20 & 1 a 1,5 & $\begin{array}{l}\text { Mai/2018 a } \\
\text { Dez/2018 }\end{array}$ & $\begin{array}{l}4 \text { usuários } \\
2 \text { trabalhadores } \\
1 \text { estudante }\end{array}$ \\
\hline Caps AD & $\begin{array}{l}2 \text { usuários } \\
2 \text { profissionais } \\
2 \text { estudantes }\end{array}$ & 30 & 1 a 1,5 & $\begin{array}{l}\text { Nov/2017 a } \\
\text { Set/2018 }\end{array}$ & $\begin{array}{l}2 \text { usuários } \\
2 \text { trabalhadores } \\
2 \text { estudantes }\end{array}$ \\
\hline
\end{tabular}

Fonte: Elaboração própria.

O material usado nas discussões dos grupos foi uma cópia do 'Guia GAM' fornecida a cada usuário $^{\mathbf{1 2}, 13}$. O Guia foi traduzido a partir do modelo canadense e foi adaptado para a realidade brasileira, conforme as demandas e necessidades observadas no contexto sociocultural e sanitário do país. Através dessa cartilha, foram trabalhados diversos aspectos, como autoconhecimento, direitos dos usuários, conceito de autonomia e relação com o medicamento e as suas influências na vida dos participantes. Destinado aos usuários, divide-se em duas partes, subdivididas em 'Passos' (tópicos). A 'Parte 1 - Sua qualidade de vida' aborda tópicos referentes ao conhecimento sobre si mesmo e sobre os medicamentos psiquiátricos. Já a 'Parte 2 - Um caminho para mudanças', refere-se a ações de revisão do que foi trabalhado no grupo e ao planejamento de ações futuras ${ }^{12,13}$. O andamento pelo Guia se deu conforme cada grupo, até que todos os tópicos tivessem sido abordados de alguma forma, tendo esse processo uma duração média de oito meses.

Após a finalização dos grupos, todos os envolvidos foram convidados a participar de 
entrevistas semiestruturadas. Os pesquisadores do presente estudo criaram um roteiro, utilizando linguagem acessível, a fim de guiar as entrevistas. No tocante aos usuários, manteve-se o foco nas perguntas sobre as experiências individuais de terem participado do GAM, nas dificuldades encontradas nessa participação, nos efeitos em relação ao tratamento e na dinâmica com a equipe de saúde que os acompanhou. Os usuários que participaram das entrevistas vinham acompanhando o grupo de modo regular, desde seu início, contudo não houve um controle dessa frequência ao grupo. Participantes que abandonaram o grupo durante seu desenrolar não foram incluídos na pesquisa. Quanto aos estudantes e trabalhadores, o foco ficou tanto na experiência como no aprendizado que tiveram ao participarem dos grupos. Os trabalhadores que participaram dos grupos e, portanto, das entrevistas eram psicólogos, enfermeiros e farmacêuticos.

As entrevistas foram gravadas em áudio e transcritas integralmente. Cada uma delas foi identificada por meio de códigos para preservar a identidade dos entrevistados, sendo: $\mathrm{U}$ para usuários, T para trabalhadores e E para estudantes, seguidos de números sequenciais para diferenciar cada entrevista.

Os textos foram transformados em narrativas, conforme os preceitos da hermenêutica gadameriana ${ }^{\mathbf{1 4}}$, que busca o significado a partir dos fenômenos emanados dos discursos; e, a partir daí, extraíram-se os núcleos argumentais, que foram agrupados em categorias construídas conforme a interpretação dos discursos.

Para seguir a dinâmica hermenêutica, foi feito um processo de leitura detalhada inicial das transcrições, no qual se manteve o sentido das falas originais dos participantes. Buscouse, também, sintetizar os textos, enfatizando ideias repetidas. Exemplos foram apresentados de forma resumida, e os vícios de linguagem foram transformados em escrita para tornar o texto mais corrido e compreensível, sem perder a essência das falas dos participantes. Na sequência, os núcleos argumentais foram agrupados em categorias, gerando uma grade de análise (quadro 2) que possibilitou a organização e interpretação dos discursos.

Quadro 2. As categorias e os núcleos argumentais do estudo

\begin{tabular}{ll}
\hline Categorias & Núcleos argumentais \\
\hline O grupo GAM & Motivações para participar \\
& Dinâmica do grupo \\
& O guia GAM \\
& Aceitação da equipe e influência do ambiente institucional \\
Interação com o serviço & Como o grupo GAM acrescentou informações à minha vida \\
Efeitos da participação & Influência e resultado do grupo GAM \\
& Indução de mudanças nos trabalhadores \\
& A relação com os medicamentos \\
Desafios & Os desafios enfrentados pelo grupo GAM \\
\hline
\end{tabular}

Fonte: Elaboração própria.

Por fim, os pesquisadores interpretaram os pontos principais das categorias temáticas observadas nos resultados. Os argumentos que fazem parte da discussão foram extraídos das próprias narrativas construídas a partir da transcrição das entrevistas semiestruturadas e foram posicionados em uma planilha, de tal forma que cada núcleo argumental pode ser 
comparado, entre as diversas entrevistas. A presente pesquisa foi aprovada pelo Comitê de Ética e Pesquisa da UFPR, com o Certificado de Apresentação para Apreciação Ética de número 71471417.0.0000.0102.

\section{Resultados}

Os tópicos que emergiram das entrevistas foram divididos em cinco categorias de análise: A dinâmica nos grupos GAM; Interação da estratégia da Gestão Autônoma da Medicação com o serviço; Efeitos da participação no grupo GAM, quanto ao tratamento; Efeitos da participação no grupo GAM, quanto ao entendimento do problema de saúde de cada um; e Efeitos da participação no grupo GAM na reflexão da prática clínica.

\section{A dinâmica nos grupos GAM}

A motivação recorrente relatada pelos participantes-usuários foi a necessidade de falar sobre os medicamentos, somada à expectativa de um espaço de fala acolhedor. Nesse sentido, o grupo se mostrou um espaço seguro, no qual se criou um senso de pertencimento nos participantes, configurando-se como um local de socialização e compartilhamento de experiências.

Eles começaram a contar qual era a rede de apoio deles, até que um falou que aquele grupo era como um confessionário porque ali eles realmente se sentiram à vontade de falar sobre a vida deles e, abertamente, falar sobre a medicação. (Entrevista T03).

Os participantes relataram gostar do Guia, entendendo-o de forma clara e fácil, como um bom norteador do processo e das atividades do grupo, fomentando debates e reflexões, contribuindo com o aprendizado e estudo de uma forma didática, além de auxiliar no processo de autoconhecimento. Em poucos casos, o entendimento ficava dificultado, e os profissionais buscavam alternativas para lidar com o entrave: no caso de uma participante analfabeta, o uso do Guia foi facilitado, tanto pelas próprias participantes e mediadoras do grupo quanto por vizinhas e outras pessoas da rede de apoio.

Os profissionais de saúde também identificaram a estratégia como espaço de troca de experiências e informações entre os membros. Perceberam que a construção de conhecimento dentro do grupo foi coletiva, e isso potencializou o aprendizado, tanto de conteúdos técnicos como de assuntos relacionados à vida diária.

Questões como autoconhecimento, redes de apoio durante o tratamento, direitos dos usuários, autonomia, relação com os medicamentos em uso, bulas, interrupção do uso do medicamento e prognóstico do tratamento foram tratadas durante os grupos. Todos esses tópicos surgiram através de perguntas e questionamentos que o Guia suscitou, e tanto os trabalhadores como os usuários consideraram que a dinâmica favoreceu uma abordagem reflexiva sobre esses temas. Sendo assim, o Guia se mostrou um norteador de reflexões durante as reuniões, fomentando debates e contribuindo com o aprendizado dos participantes.

As entrevistas demonstraram que, no início, os grupos costumavam seguir a lógica sequencial proposta pelo Guia. Conforme o tempo avançou e o grupo ganhou confiança, o direcionamento se tornou mais livre, sendo, inclusive, fomentada a busca por conteúdos que extrapolavam o Guia.

\section{Interação da estratégia da Gestão Autônoma da Medicação com o serviço}

A aceitação dos profissionais em relação à estratégia GAM não foi consenso em todos os serviços onde foi posta em prática. Alguns trabalhadores sentiram resistência na equipe de saúde, pois ela associava a estratégia da GAM à retirada do medicamento e, consequentemente, à ocorrência de crises. 
[...] no início, tivemos bastante resistência da equipe. Eles achavam que GAM era só retirada de medicação, associavam a participação no GAM à ocorrência de crises. Abrimos pra dez pessoas e nenhum TR [trabalhador de referência] inscreveu ou convidou nenhum paciente. (Entrevista T04).

Alguns trabalhadores relataram que, quando informavam aos usuários seus direitos, temiam sentirem-se cobrados pelo estado, uma vez que viviam o papel interseccional de cidadãos e representantes desse estado. Afinal, são os trabalhadores, os representantes destes mesmos serviços, que não têm condições de fornecer o que lhes é pedido. Assim, sentem-se receosos de que, caso os usuários parem de tomar medicamentos, a culpa e a cobrança por parte do estado recaiam também sobre eles mesmos, os trabalhadores.

Outros trabalhadores observaram que a realização do grupo em um ambiente institucional reforçou a dificuldade de tratar a perspectiva da horizontalidade, uma vez que esses espaços possuíam uma lógica hierarquizada e funções-papéis já bem estabelecidas e cristalizadas.

[O que] mudou é não ter medo de falar para o paciente dos efeitos colaterais que poderiam aparecer. Às vezes, a gente não falava de medo do paciente parar de tomar. (Entrevista T03).

\section{Efeitos da participação no grupo GAM, quanto ao tratamento}

Os diálogos promovidos no grupo proporcionam aprendizados, tanto para usuários quanto para trabalhadores e estudantes. Em especial, os participantes relataram ter aprendido sobre efeitos colaterais de medicação (tanto psiquiátrica quanto clínica), que, muitas vezes, podem aparecer antes do efeito terapêutico desejado. Para além dos momentos no grupo, os usuários sentiam-se motivados a buscar informações por conta própria.
A gente aprendeu muito efeitos indesejáveis. Um caso que me chamou a atenção foi da fluoxetina. Uma paciente disse que dava muita coceira nela. Eu fiquei surpresa e fui buscar na literatura. $E$, realmente, $0,4 \%$ das pessoas que tomam, podem ter coceira. (Entrevista T02).

Os usuários destacam como pontos de grande importância: o aprendizado referente à razão pela qual a medicação foi prescrita; qual seria a ação terapêutica, ou a contraindicação; e em quais quadros podem ser indicados - às vezes, um mesmo medicamento para quadros distintos. Referem que, muitas vezes, desconhecem o porquê de estarem tomando determinado medicamento. Tal fato foi associado a eventos anteriores durante seu histórico de tratamento, que, a partir do aprendizado no grupo GAM, percebem como sendo práticas violentas.

Antes, não era explicado o porquê de tomar o remédio. Hoje, eu sei, devido ao aprendizado com o GAM, que eu, muitas vezes, fui contido com medicação. Um histórico de violência. Jáfui amarrado em hospital. Mas nada era explicado - tem que tomar e acabou. Em hospital, ou tomava oral, ou injetável. Essa é a importância do nosso encontro do GAM, pra conhecer mais sobre medicação. Não somente o efeito, mas pra quê tomar. (Entrevista U01).

Os usuários observaram diferenças nas formas de tratamento que receberam ao longo da vida. Avaliaram mudanças no posicionamento e na relação com os profissionais e também em relação às informações oferecidas. Foi perceptível que, anteriormente, as práticas de tratamento que receberam, em muito se pautavam na violência, na hierarquização e na medicamentalização. Esta mudança na forma de tratamento contribui também para uma mudança nos próprios usuários, que passam a se perceber como indivíduos com direitos. Relatam que $\mathrm{o}$ aprendizado sobre seus direitos, muitas vezes, lhes era negado.

Se eu tivesse esse conhecimento sobre a medicação e meus direitos, eu ia atrás. Parece que a gente era 
proibido de ter conhecimento, era restrito. Então, eu jamais pensei que ia ter um grupo assim. Eu nunca estava de frente com o profissional, escutando o que ele diz e falando minha ideia. (Entrevista U03).

Alguns participantes, usuários e profissionais, relataram que, apesar de reconhecerem a importância da medicação, se relacionavam de modo ambivalente com ela, pois gostariam de não tomá-la. Já outros usuários, compreendem o medicamento com um papel fundamental em suas vidas, e principal responsável por seus tratamentos e pela manutenção da ausência de crises. O medicamento como objeto que, em si só, apresentaria a solução e/ou cura para o problema apresentado.

Por outro lado, o grupo buscou trabalhar outras visões do medicamento, entendendo-o como um recurso terapêutico possível e, muitas vezes, necessário, porém não o único, e não imprescindível em todos os casos.

O grupo sempre proporcionou reflexões em relação à tomada de medicação com o intuito de entender o que movimenta determinado comportamento, muito mais do que apenas aspectos técnicos do ponto de vista biológico-orgânico.

\section{Efeitos da participação no grupo GAM, quanto ao entendimento do problema de saúde de cada um}

Os usuários relataram que a participação no grupo contribuiu para o desenvolvimento de reflexão, percepção de si e da vida. O processo de autoconhecimento e conscientização, muitas vezes, já vinha sendo construído ao longo do tratamento, mas os usuários referem que a participação no grupo o potencializou. Sujeitos cada vez mais conscientes de si, de seus limites e potencialidades, da vida que possuem e daquilo que desejam, encontrando novas formas de encarar os problemas e descobrir fatores de bem-estar, que agregaram ao cotidiano. A GAM contribuiu para a construção e o reconhecimento da identidade dos participantes. Usuários que antes se associavam muito à doença e ao seu tratamento, a partir do trabalho no grupo, passaram a olhar para si mesmos como sujeitos detentores de vida e autonomia.

Por outro lado, alguns trabalhadores não observaram essa mesma mudança percebida pelos usuários, ou seja, para eles, não houve um comportamento mais questionador por parte dos usuários em relação ao seu tratamento, ao serviço ou às condutas dos profissionais de saúde. Para os trabalhadores, isto ocorre devido à manutenção de uma lógica de cuidado hierarquizada e médico-centrada.

Apesar de ser um serviço dito multiprofissional, o médico, muitas vezes, ainda é o centro. Então, eles [usuários] ainda não conseguem questionar, têm dificuldade. (Entrevista T04).

\section{Efeitos da participação no grupo GAM na reflexão da prática clínica}

Os trabalhadores relatam que, pelo fato de o Guia propiciar perguntas que são postas a todos, ficaram instigados a respondê-las e contar as próprias experiências. Esse movimento trouxe a percepção de que estavam mais próximos dos usuários, estreitando-lhes os vínculos e corroborando a importância da GAM para construir horizontalidade nos serviços de saúde e nas relações terapêuticas. Reforçam que esta conformação não aparece em outros grupos ou atividades nos serviços de saúde. Esse mesmo resultado foi observado no relato das estudantes de medicina, uma mudança de olhar em relação aos participantes, com maior igualdade e proximidade.

Poder falar de quem eu sou. Eles se veem mais confiantes em saber que a gente não é dono do saber. Então, quando eu falo no GAM, parto de um 'Não sei, vamos construir juntos?' e é bem gratificante. Eles também falam 'Ela não sabe tudo'. Isso me colocou a refletir sobre minha atuação como terapeuta. (Entrevista T04). 
O olhar em relação ao saber do usuário também mudou. Alguns profissionais relataram, por exemplo, perceber que os usuários entendem mais de medicação do que se supunha, ou que, muitas vezes, imaginavam que a adesão ao tratamento farmacológico era conforme prescrição médica, demonstrando uma não percepção profissional da autonomia da pessoa sobre sua própria vida, posicionamento comum em um sistema de cuidado hierarquizado e que tende à tutela. Além disto, alguns profissionais indicam que o grupo promoveu uma reflexão crítica a respeito de suas próprias práticas, por identificarem falhas que poderiam ser sanadas a partir de uma melhor atuação profissional.

Os estudantes de medicina citaram que a experiência de participar da estratégia GAM possibilitou vivenciar, na prática, conceitos imprescindíveis dentro da medicina, como a importância de valorizar as falas e experiências das pessoas. Assim como entender que autonomia e empoderamento são condições básicas, que precisam ser garantidas às pessoas, na prática, pelos profissionais de saúde.

A participação no grupo foi uma preparação para eu ser um futuro profissional porque eu acho que a maioria dos profissionais não tem essa consciência quando saem da faculdade. Eu mesmo nunca tinha ouvido falar sobre empoderamento do paciente, direito sobre tratamento, e eu acho que eu ter isso numa atividade de extensão do curso vai fazer uma diferença enorme. (Entrevista E01).

A mais evidente dificuldade sentida pelos profissionais foi a de sair do papel de detentor do conhecimento, daquele que se responsabiliza em maior parte pelo tratamento do outro. Sentiram que, muitas vezes, os próprios usuários esperavam posicionamentos dos profissionais, entendendo que a resposta 'correta' deveria surgir da figura com maior proximidade do saber técnico.

\section{Discussão}

\section{O lugar do medicamento e suas relações}

O medicamento pode ocupar muitos espaços na vida dos usuários. Muitas vezes, ainda é visto como principal ou único responsável pelo tratamento, ocupando um espaço de 'pílula mágica'. Outras tantas, ocupa lugar indesejado, sendo seu uso rejeitado, mas, ainda assim, desempenha o papel de causador de problemas de variadas matizes ${ }^{4,8}$. No presente estudo, observou-se, em muitos casos, o medicamento como ponto principal do tratamento, em paralelo a outros nos quais há uma tentativa de racionalizar seu uso, refletindo sobre alternativas terapêuticas e sobre o significado do uso da medicação. Outros trabalhos também apontam o medicamento ainda como ponto central do cuidado, sendo o uso do psicofármaco entendido como sinônimo de realização de tratamento, revelando a manutenção de uma lógica biomédica de cuidado ${ }^{15,16}$.

Apesar de ocupar lugar de grande importância, pouco se fala da medicação de modo esclarecedor. Uma das principais motivações para os usuários participarem do grupo GAM é poderem falar e conhecer mais sobre os medicamentos que utilizam, resultado também observado em outros estudos 6,9,15. É comum que os usuários relatem não saberem qual a razão pela qual tomam a medicação, para quê ela serve, bem como outras informações pertinentes. Assim como também são rotineiros os relatos dos usuários referentes à dificuldade de conversar com os profissionais de saúde - em especial, os médicos - sobre suas medicações e seus tratamentos, e os profissionais tampouco são proativos em fornecer informações claras e abundantes. Sendo assim, as dúvidas e o desconhecimento sobre as medicações são muitos.

Esses mesmos estudos identificam que a dificuldade de falar sobre a medicação é tanto de usuários para com profissionais quanto entre os próprios profissionais. Observa-se 
que profissionais não médicos acabam se apropriando pouco do tema, delegando-o aos profissionais médicos, o que reforça a centralização das decisões do tratamento e desestimula o debate e a apropriação do tema por todos. Identificam alguns problemas associados a esta dificuldade: relações desiguais de poder, coerção, medo, timidez, uso de linguagem técnica, ausência de escuta para a vivência pessoal e atribuição exclusiva de competências ao médico ${ }^{6,9,15,16}$.

\section{Repensando as relações entre trabalhadores e usuários}

Historicamente, o lugar do tratamento é justamente o oposto ao que propõe a estratégia GAM e, ainda hoje, podem-se observar práticas de cuidado em saúde hierarquizadas, dependentes e de pouco diálogo. Algumas pesquisas envolvendo a GAM demonstraram que, apesar dos relatos dos usuários, de maior participação no tratamento, existe uma dificuldade de encontrar exemplos concretos de alteração na estrutura da relação usuário-tratamento ou usuário-profissional, muito por conta da própria organização estrutural do sistema e devido a fluxos de trabalho e papéis pré-estabelecidos.

Assinala-se que, quando o trabalhador da saúde suspende o poder que lhe é chancelado dentro das instituições de saúde, passa a identificar e, por conseguinte, coloca em análise elementos simbólicos, míticos e reais do poder e do uso dele no campo da saúde. Sem a análise sobre essas dimensões, nunca se operarão mudanças na estrutura formal do poder institucional17. O grupo GAM, por se tratar de uma intervenção fora da lógica institucional na qual os profissionais de saúde trabalhavam, propiciou essa suspensão temporária e permitiu que alguns trabalhadores experimentassem o espaço do grupo como algo terapêutico também para si.

Motivados pela metodologia proposta pela estratégia GAM, os profissionais que participaram e/ou atuaram como mediadores do grupo tiveram que falar sobre suas experiências pessoais e buscar uma postura de construção coletiva dos saberes, a partir da troca de experiência e de informações técnicas. Esse movimento foi relatado como benéfico pelos entrevistados, afinal, é cobrado dos trabalhadores da saúde um outro padrão de relacionamento, no qual a 'excelência', a 'eficácia' e a 'produtividade' são valorizadas nos formatos gerencialistas de gestão atual ${ }^{18}$. Ademais, é observado que os trabalhadores da saúde, ao viverem em contato constante com o sofrimento, se identificam com ele ${ }^{19}$. Mas não apenas isto: condições precárias de atuação e processos verticalizados de gestão implicam em altas taxas de sofrimento e adoecimento no trabalho ${ }^{20}$. Na tentativa de se defenderem deste cenário desagradável, as equipes desenvolvem diversos mecanismos, seja a burocratização do trabalho, sejam o isolamento e a discriminação maior entre 'o nós' e 'os outros', e, assim, montam fortes barreiras, evitando se colocar em contato com esse sofrimento, ou, ainda, tornam-se retaliadoras com os usuários. Lidar com estas dimensões requer dispositivos de trabalho que permitam restabelecer espaços subjetivos conjuntos ${ }^{9}$.

No cenário atual, o já subfinanciado sistema de saúde brasileiro tem uma perspectiva de arrocho ainda maior com a já aprovada emenda constitucional do 'teto dos gastos'. Ademais, a mudança da política de saúde mental nos últimos anos deixa clara a perspectiva de redução do financiamento dos serviços de saúde comunitários, atingindo principalmente os Caps $^{3}$. E isto atinge exatamente atividades como a GAM, que estão fora do escopo do gerencialismo ${ }^{\mathbf{1 8}}$ e exigem equipes estáveis, com educação permanente, para um manejo mais horizontal dos grupos.

\section{Conhecendo direitos e possibilidades de aprendizagem e formação}

De acordo com as entrevistas, muitos relataram ter aprendido sobre seus direitos apenas participando do grupo, e isto é evidenciado em outras pesquisas sobre o tema ${ }^{3,9}$. 
Identifica-se que os usuários no campo da saúde mental têm dificuldade de se reconhecerem como sujeitos de direitos, por conta não somente da não percepção do que se configura como direito, como também do lugar histórico que a sociedade reserva ao 'louco': um sujeito que não responde pelos seus atos e, portanto, não pode assumir um papel de cidadão ${ }^{21}$.

Contudo, o fato de os usuários tomarem conhecimento dos direitos que possuem e buscarem agir no sentido de garanti-los, não garante que tais direitos se concretizarão na realidade. Estudos apontam que o acesso à informação sobre direitos dos usuários é importante, porém não suficiente, pois, por si só, não garante a consolidação de um sujeito de direitos, ou seja, que haja o reconhecimento, pelo outro, do direito já reconhecido pelo usuário ${ }^{\mathbf{8} 22}$. É necessário legitimar o sujeito de direitos, fazendo valer socialmente os direitos do usuário. A participação em espaços de controle social e em movimentos sociais organizados, bem como o fortalecimento destes espaços e instâncias, podem contribuir para a reivindicação de direitos e a garantia de legitimação destes ${ }^{23}$.

A comunicação em saúde pode apresentar-se como uma ação paternalista ou coprodutora de sujeitos. Nos dias de hoje, a comunicação e a educação em saúde são centradas no modelo médico-curativo, com fortes influências comportamentais que delineiam a ação educativa na modificação mesmo do comportamento ${ }^{24}$. O Roteiro do Guia GAM é problematizador, uma vez que se utiliza mais de perguntas do que de textos informativos como parte de sua dinâmica. A concepção de educação problematizadora tem caráter reflexivo, implicando um constante ato de desvelamento da realidade, buscando uma inserção nesta realidade, conduzindo à mudança25. É interessante ressaltar que alguns sujeitos contaram que a GAM os estimulou a pensar, junto com os usuários, dinâmicas como teatros e leituras conjuntas, ao trabalharem com o Guia.

Por mais problematizadora que seja a estratégia GAM, não é possível relacionar todas as mudanças que apareceram nas narrativas exclusivamente à sua vivência. Afinal, foram oito meses, em média, entre o início e o final dos grupos. O próprio Guia, em si, necessitaria de uma atualização, uma vez que a temática dos direitos, desde quando ele foi traduzido e adaptado, em 2012, já possui novas questões que atravessam os anos 2020. Além disso, apesar de o Guia funcionar como um norte, os manejos de cada moderador no grupo eram diferentes, o que também influenciou os resultados, que foram dependentes da condução de cada grupo. Por isto, é importante ressaltar que, por mais que a estratégia tenha um formato para mútua ajuda, a existência de profissionais capacitados para um manejo grupal que não seja tutelar e valorize a experiência do outro torna-se essencial.

Coloca-se, também, como limitação do estudo, o fato de a escolha dos usuários ter sido realizada pelos próprios profissionais do Caps, o que pode ter limitado a diversidade dos participantes. Além disso, pelo fato de as entrevistas terem sido realizadas por pesquisadores que os participantes do grupo não conheciam, estes podem não ter se sentido completamente à vontade para expressar suas opiniões.

Para os estudantes que participaram da pesquisa, valeu como instrumento de formação a partir do reconhecimento de uma autoridade proveniente do usuário, facilitando o respeito ao poder que dela advém. Aqui se evidencia um papel de desconstrução que a GAM desempenhou. Tal premissa é importante para inserir a experiência dos usuários como metodologia de ensino, valorizando não apenas o saber técnico, o olhar externo, mas também as diversas vozes que, muitas vezes, não aparecem nos caminhos formativos. Na pesquisa GAM, muitos trabalhadores relataram possuir um conhecimento prévio acerca dos usuários, permeado de certezas e predefinições. No momento em que tiveram contato com as singularidades de cada usuário, perceberam que mesmo o conhecimento de efeitos e ações de medicamentos era incerto. Interessante foi que, quando as certezas viraram incertezas, a 
segurança aumentou. Surgiu um sentimento de segurança, por poderem incluir o outro nos caminhos do tratamento. Uma vez que se abalam os alicerces do construto de conhecimento científico como solução prêt-à-porter, fortalece-se a crença no outro para a construção de um novo conhecimento. Tais bases possibilitaram outra maneira de se discutir autonomia, direitos dos usuários, psicofármacos e a influência desses debates na vida de cada um²6.

\section{Considerações finais}

A estratégia GAM contribuiu para estimular a construção de autonomia e empoderamento dos usuários, através da socialização de informações sobre possibilidades de tratamento e de seus direitos, além da promoção de um espaço de compartilhamento de experiências e reflexões, buscando o autoconhecimento e desenvolvimento de consciência crítica sobre o uso da medicação e sobre o tratamento.

A autonomia e o empoderamento no uso dos medicamentos e no tratamento estão em entender o significado do uso, não apenas em seus aspectos farmacológicos, mas sim, e principalmente, em seu significado (ou seus significados) dentro do contexto da vida do usuário. Seu desenvolvimento ocorreu como entendimento do processo: o porquê de tomar, para quê tomar, em que medida isto se relaciona com outros aspectos da vida. Mesmo que não haja perspectiva de retirada da medicação ou que seja necessário auxílio para o uso, a grande mudança está nas relações - seja a relação com o medicamento, seja a relação com os profissionais de saúde ou outros usuários.
O grupo GAM também se apresentou como um importante espaço de socialização e construção de vínculos, contribuindo para o aspecto de reinserção social, fundamental no tratamento em saúde mental. Construir relações horizontais, pautadas na fala e na escuta, na garantia de direitos, na autopercepção de si e de suas responsabilidades perante a vida é construir autonomia.

Contudo, ainda se observa a manutenção de um sistema com práticas biomédicas, pautadas na tutela, centradas no saber e no poder médico, e hierarquizadas, dificultando a consolidação da estratégia GAM e seus resultados, e a efetivação de um sujeito de direitos. Esta questão é aprofundada com o cenário atual de desinvestimentos na rede de atenção psicossocial territorial e também com a alta demanda, o número reduzido de trabalhadores e os recursos escassos e/ou mal direcionados, conforme observado em outros estudos. Portanto, entende-se que, em paralelo, é fundamental o comprometimento político-administrativo com o investimento e a efetivação de políticas em saúde mental pautadas nos pressupostos da Reforma Psiquiátrica e na Luta Antimanicomial.

\section{Colaboradores}

Santos DVD (0000-0002-1198-1890)*, Federhen C (0000-0001-7494-6892)*, Silva TA (0000-0001-8510-9045)*, Santos IR (0000-0002-0517-0389)*, Levino CA (00000002-7790-2278)*, Onocko-Campos RT (0000-0003-0469-5447)*, Stefanello S (00000002-9299-0405)* contribuíram igualmente para a elaboração do manuscrito. 


\section{Referências}

1. Thornicroft G, Tansella M. Quais são os argumentos a favor da atenção comunitária à saúde mental? Pesqui prát psicossociais. 2008; 9-25.

2. Pinho ES, Souza ACS, Esperidião E. Processos de trabalho dos profissionais dos Centros de Atenção Psicossocial: revisão integrativa. Ciênc. Saúde Colet. 2018; 23:141-52.

3. Cruz NFO, Goncalves RW, Delgado PGG. Retrocesso da reforma psiquiátrica: o desmonte da política nacional de saúde mental brasileira de 2016 a 2019. Trab. educ. saúde. 2020 [acesso em 2020 ago 23]; 18(3):e00285117. Disponível em: https:// www.scielo.br/scielo.php?script=sci_arttext\&pid $=$ S1981-77462020000300509.

4. Del Barrio LR, Cyr C, Benisty L, et al. Autonomous Medication Management (GAM): new perspectives on well-being, quality of life and psychiatric medication. Ciênc. Saúde Colet. 2013; 18:2879-87.

5. Dahl CM. Experiência, narrativa e intersubjetividade: o processo de restabelecimento ("recovery") na perspectiva de pessoas com diagnóstico de esquizofrenia em tratamento nos centros de atenção psicossocial. [dissertação]. Campinas: Universidade Estadual de Campinas; 2012

6. Santos DVD, Onocko-Campos R, Basegio D, et al. Da prescrição à escuta: efeitos da gestão autônoma da medicação em trabalhadores da saúde. Saúde Soc. 2019; 28:261-71.

7. Jorge MSB, Campos RO, Pinto AGA, et al. Experiências com a gestão autônoma da medicação: narrativa de usuários de saúde mental no encontro dos grupos focais em centros de atenção psicossocial. Physis. 2012; 22:1543-61.

8. Gonçalves LLM, Onocko Campos RT. Narrativas de usuários de saúde mental em uma experiência de gestão autônoma de medicação. Cad. Saúde Pública [online]. 2017 [acesso em 2020 ago 23]; 33:e00166216.
Disponível em: https://www.scielo.br/scielo. php?pid=S0102-311X2017001105002\&script $=$ sci abstract\&tlng=pt.

9. Favero CP, Rodrigues J, Silva IP, et al. Grupo de gestão autónoma da medicação num centro de atenção psicossocial: experiência de usuários. Rev. Enf. Ref. 2019; (21):91-100.

10. Engel GI. Pesquisa-ação. Educar em Revista. 2000; (16):181-91.

11. Teixeira PM, Neto Megid J. Uma proposta de tipologia para pesquisas de natureza interventiva. Ciênc. educ. (Bauru). 2017; 23(4):1055-1076.

12. Onocko Campos RT, Passos E, Palombini A. Gestão Autônoma da Medicação - Guia de Apoio a Moderadores. 2014 [acesso em 2019 out 10]; 1(1):1-44. Disponível em: http://www.fcm.unicamp.br/fcm/laboratorio-saude-coletiva-e-saudemental-interfaces.

13. Onocko Campos RT, Passos E, Leal E, et al. Guia da Gestão Autônoma da Medicação - GAM. 2012. [acesso em 2020 ago 1]. Disponível em: https://www.fcm. unicamp.br/fcm/laboratorio-saude-coletiva-e-saude-mental-interfaces; 2012.

14. Ricoeur P, Japiassu H. Interpretação e ideologias: Francisco Alves; 1983.

15. Onocko Campos RT, Passos E, Palombini AL, et al. A Gestão Autônoma da Medicação: uma intervenção analisadora de serviços em saúde mental. Ciênc. Saúde Colet. 2013; 18:2889-98.

16. Freitas ACM, Reckziegel JB, Barcellos RC. Empoderamento e autonomia em saúde mental: o guia GAM como ferramenta de cuidado. Saúde (Santa Maria). 2016; 42(2):149-56.

17. Onocko Campos RT. Humano, demasiado humano: un abordaje del mal-estar en la institución hospitalaria. In: Spinelli H, organizador. Salud Colectiva: Cul- 
tura; Instituciones; Subjetividad Epidemiología, Gestión y Políticas Buenos Aires: Lugar Editorial. 2004. p. 103-20.

18. Newman J, Clarke J. Gerencialismo. Educ. Real. 2012; 37(2):353-381.

19. Onocko Campos RT. O encontro trabalhador-usuário na atenção à saúde: uma contribuição da narrativa psicanalítica ao tema do sujeito na saúde coletiva. Ciênc. Saúde Colet. 2005; 10:573-83.

20. Katsurayama M, Parente RCP, Moraes RD, et al. Trabalho e sofrimento psíquico na Estratégia Saúde da Família: uma perspectiva Dejouriana. Cad. Saúde Coletiva. 2013; 21(4):414-9.

21. Tilio R. "A querela dos direitos": loucos, doentes mentais e portadores de transtornos e sofrimentos mentais. Paidéia. 2007; 17(37):195-206.

22. Emerich BF, Campos RO, Passos E. Direitos na loucura: o que dizem usuários e gestores dos Centros de Atenção Psicossocial (CAPS). Interface. 2014; 18:68596.
23. Guimarães JMX, Jorge MSB, Maia RCF, et al. Participação social na saúde mental: espaço de construção de cidadania, formulação de políticas e tomada de decisão. Ciênc. Saúde Colet. 2010; 15:2113-22.

24. Gazzinelli MF, Gazzinelli A, Reis DC, Penna CMM. Educação em saúde: conhecimentos, representações sociais e experiências da doença. Cad. Saúde Pública. 2005;21:200-6.

25. Freire P. Pedagogia do oprimido. 17. ed. Rio de Janeiro: Paz e Terra. 1987.

26. Emerich F, Onocko Campos RT. Formação para o trabalho em Saúde Mental: reflexões a partir das concepções de Sujeito, Coletivo e Instituição. Interface (Botucatu). 2019 [acesso em 2020 ago 2020]; 23:e170521. Disponível em: https://www.scielo.br/scielo.php?script=sci_abstract $\&$ pid $=$ S1414$-32832019000100212 \& \operatorname{lng}=$ en\&nrm=iso\&tlng=pt.

Recebido em 13/12/2019

Aprovado em 15/08/2020

Conflito de interesses: inexistente

Suporte financeiro: não houve 